\title{
ÉLITES Y POLÍTICA EN EL ASTILLERO DE LA HABANA DURANTE EL SIGLO XVIII
}

\author{
José Manuel Serrano Álvarez \\ Universidad de Antioquía, Colombia
}

\begin{abstract}
RESUMEN. La madera no solo era el elemento estructural básico e indispensable de los buques del siglo XVIII, sino que además constituía un factor decisivo en el progreso técnico-tecnológico que encerraba la construcción naval. Sin embargo, el acceso al maderamen no siempre fue fácil, ya que se trataba de un recurso necesitado por la práctica totalidad de la población. Con una demanda alta y una crónica carencia de infraestructura de accesos y comunicaciones en las zonas productoras de madera, este vital aspecto de la construcción se transformó en un objetivo estratégico de primer orden, tanto en España como en Cuba. Este artículo tratará de profundizar en el rol de la madera cubana para la renaciente armada española en el siglo XVIII y el subsiguiente problema político (y económico) con las élites locales para que la monarquía lograra el ansiado equilibrio entre ambas facciones.
\end{abstract}

Palabras claves: madera, navío de línea, Cuba, La Habana, élites.

ABSTRACT. In the ships of the $18^{\text {th }}$ century, the wood was not only the basic and indispensable structural element, but it also constituted a decisive factor in the technical-technological progress that enclosed shipbuilding. However, access to timber was not always easy since it was a resource needed by practically the entire population. With a high demand and a chronic lack of access and communication infrastructure in the wood producing areas, this vital aspect of construction became a strategic objective of the first order, both in Spain and in Cuba. This article will try to deepen the role of Cuban wood for the resurgent of Spanish Armada in the 18th century and the subsequent political (and economic) problem with local elites so that the Monarchy achieved the desired balance between both factions.

Keywords: wood, ship of the line, Cuba, La Havana, elites.

Recibido: 12-3-2019 • Aceptado: 17-6-2019 • jmserranoalvarez@gmail.com 


\section{La importancia de la madera en Cuba}

La relación entre la madera y la construcción naval en La Habana es tan antigua como la propia presencia de los españoles en Cuba. En efecto, a principios del siglo XVII se hicieron denodados esfuerzos por aumentar el ritmo de construcción naval en América, y Cuba se destacó en seguida como el lugar competente. A tal efecto, el 13 de marzo de 1607 se reunió en Sevilla una comisión especial para poder determinar el grado de idoneidad del proyecto constructivo en La Habana que, integrada por el alcaide Bernardino Delgadillo, Francisco de Nart y Juan Bautista de Broca, determinó que el puerto y la ciudad tenían suficiente abundancia de materiales y calidad en las maderas como para sostener dicho proyecto (Pichardo, 1973, p. 123). Esta es una de las primeras referencias que tenemos de la importancia de la madera cubana en relación con la posición de La Habana como puerto principal del Caribe y lugar preferente para la construcción de buques de guerra.

Sin embargo, y también desde el inicio, el uso y disfrute de la madera originó fuertes disputas y controversias con las élites mercantiles y agropecuarias locales. Así, ya en 1619 la canalización del esfuerzo naval en La Habana y el extensivo uso de las maderas provocó fricciones legales con la población local. El capitán Juan Pérez de Oporto, que se había convertido en el principal constructor de naves en La Habana al hilo de la resolución de Sevilla de 1607, protagonizó un largo litigio con los ganaderos por el uso de las maderas; uso que entendían estos últimos como lesivos para sus intereses de cara a la exportación de sus productos. Finalmente, el asunto acabó llegando al Consejo de Indias, donde una Real Cédula, fechada el 2 de marzo de 1620, falló a favor del capitán —y, por tanto, de los intereses de la monarquía—, provocando al mismo tiempo una protesta general de los ganaderos ante el gobernador (García Fuentes, 1991, p. 608). Este aspecto - disputas en torno a la madera y la construcción naval - se convirtió en recurrente entre las élites locales y los responsables del astillero, no solo a causa del negocio de la madera, sino también como consecuencia de la creciente posibilidad de generar redes clientelares por el uso político y mercantil del maderamen.

Conforme La Habana fue ganando preeminencia política desde finales del siglo XVII, las opciones de convertirse en el núcleo central constructivo de navíos adquirieron mayores probabilidades. Estas opciones estuvieron canalizadas principalmente en relación a la construcción naval y, por ende, de la madera. De hecho, cuando en la década de 1710 se propuso y estudió la posibilidad de crear un gran astillero en América, La Habana ganó claramente la partida a las demás candidatas a causa de sus maderas y el notable circuito de las mismas entre las élites locales (Quintero, 2004, p. 9). La abundancia, fama y fácil acceso a las mismas había jugado un histórico papel 
en el emergente rol de la burguesía mercantil cubana, y desde luego el naciente astillero habanero no hacía sino aumentar las opciones para todos (Funes, 2000, p. 113).

Una vez se produjo la consolidación del astillero en La Habana, después de 1713, la lucha en torno al control del maderamen se incrementó exponencialmente (Serrano, 2018, p. 58). Sin embargo, estas fricciones iniciales fueron resueltas a favor de los intereses del Estado. El control que ejerció durante las primeras décadas del siglo el constructor Juan de Acosta, quien se hizo cargo no solo de la fábrica y diseño de navíos, sino también del asiento de maderas, derivó en una supeditación de los intereses de los ganaderos y hacendados locales a los deseos de expansión naval ordenados por Madrid. En este sentido, Juan de Acosta actuó con mano de hierro. Acostumbrado al dominio absoluto del astillero y con manos libres desde Madrid, fijó una política sobre el uso de la madera con fines constructivos claramente estratégica, que en aquel tiempo — décadas de 1720 a 1740 - significaba dar prioridad absoluta a la botadura de navíos de línea (Serrano, 2006, pp. 12-18). Lo interesante de estas fricciones es que no se produjeron en esta primera etapa entre los sectores privilegiados de la isla, que habían asumido su posición secundaria y veían con buenos ojos apoyar a la corona aportando maderas a cambio de suculentos beneficios, sino entre las propias autoridades del astillero. Así, el constructor Acosta, que era dueño de importantes terrenos cerca de La Habana y fiscalizaba el corte de maderas de manera completa con el apoyo de gran parte de los hacendados, tuvo enormes problemas jurisdiccionales y de control de este maderamen con el comisario de Marina Juan Pinto y el rival constructivo de Acosta, Pedro de Torres. Aunque Torres y Pinto hicieron frente común contra Acosta, éste demostró tener mejores conexiones políticas tanto en Madrid como en la isla y el constructor continuó con su monopólico control de la madera para fines constructivos.

Las relaciones políticas en el seno del astillero fueron en esta etapa claves. Tradicionalmente el acceso a la madera había sido libre en Cuba al no existir una legislación precisa sobre su uso y disfrute. La abundancia de la misma y el hecho de que hasta la década de 1710 no funcionara oficialmente el astillero real de La Habana, propiciaron que los acuerdos entre las elites locales y Acosta - y entre éste y Madrid - fuesen el factor decisivo. Es de esta manera como se puede comprender que los ganaderos y hacendados se plegasen a los intereses del astillero, reservándose maderas para su uso mercantil e industrial, al tiempo que no ponían impedimentos a Acosta para el acceso a la madera para la Maestranza. De hecho, la contrata personal de que disfrutaba el propio Acosta se sirvió para utilizar a los hacendados como suministradores o intermediarios de la madera para los navíos. A pesar de la reluctante discrepancia entre las autoridades portuarias — más una disputa de egos y autoridad que otra cosa-, Acosta hizo valer este hecho y sus contactos políticos para trasladar toda la necesaria hacia el astillero sin mayores dificultades. 
En efecto, el ministro Patiño fue su gran valedor en Madrid, lo mismo que su principal protegido y posterior ministro de Marina e Indias, José del Campillo. Éste había sido comisario de Marina en La Habana entre 1719 y 1725 y en esa etapa ocupaba el cargo de Intendente General de Marina (Perona, 1998, p. 394). Fruto de estas relaciones políticas de primer orden, Acosta pudo obtener en 1737 el asiento de suministro de madera para el arsenal de Cádiz al tiempo que controlaba toda la habanera ${ }^{1}$. El secreto de este omnímodo control estribaba en la relación personal de Acosta con la élite local desde hacía al menos dos décadas, así como en la aparente generosidad de sus servicios a la monarquía. No hay que olvidar que los Acosta formaban un auténtico clan. Salvador y Pedro, padre y hermano de Juan de Acosta, habían adelantado 12.000 pesos en 1725 para el corte de maderas sin esperar siquiera el beneplácito de Madrid $^{2}$. De este generoso servicio se había aprovechado el propio constructor para hacer valer su posición en el astillero frente a sus rivales, presentando sus relaciones con la élite local (y los servicios familiares al rey) como la carta perfecta para seguir manteniendo el monopolio de la madera dentro y fuera de La Habana. Ni siquiera la presencia de Lorenzo Montalvo como comisario de Marina desde 1730 afectó la distribución y uso de la misma con fines constructivos, a pesar de que ambos personajes acabarían teniendo graves desencuentros. De hecho, la construcción del nuevo arsenal en La Tenaza en 1735 guardó relación directa con las necesidades de aumentar el volumen de suministro de madera ante los crecientes planes de fábrica naval ordenados por Madrid (Serrano, 2018, p. 78).

\section{Controversias y luchas por la madera}

La controversia sobre el uso y control de la madera tuvo una relación directamente proporcional con el rol de Montalvo como comisario de Marina y sus - en general- buenas relaciones con el gobernador de turno y las élites locales. Montalvo pertenecía a esa rancia élite cubana enraizada y endogámicamente ligada con las principales familias de la isla (Gárate, 1999, pp. 617-633). Su posición social y sus conexiones con Madrid le granjeaban capacidad para competir con los vínculos políticos isleños y peninsulares del propio Acosta y le abrían el paso a las relaciones con la poderosa élite militar cubana, también poderosa en términos económicos y financieros (Amores, 2015, p. 9). Fruto de este nuevo panorama, el control de la madera se convirtió en parte de la lucha por el poder en el astillero en medio de un ambicioso

Archivo General de la Marina Álvaro de Bazán (en adelante AGMAB), Arsenales, 5514, f. 12.

Archivo General de Indias (en adelante AGI), Santo Domingo, 379, carta de 9 de septiembre de 1725 . 
programa constructivo centrado en La Habana. Por eso, desde la década de 1730, y muy especialmente desde la de 1740, Montalvo comenzó a fiscalizar el antes poder total que tenía Acosta y sus clanes sobre el uso de la madera. Así, remitió al constructor diversas órdenes, en algunos casos con veladas amenazas, sobre qué y cómo se debería aprontar esa madera al astillero, sobre su control, distribución y precios. Igualmente, le dejó muy claro que en adelante las futuras disputas con los ganaderos locales sobre la tala debían ser resueltas por el gobernador, y no, como hasta ahora, haciendo valer sus particulares relaciones con las élites (Serrano, 2018, p. 69).

Aunque una buena parte de la élite hacendada se avenía a colaborar bien con Acosta bien con Montalvo respecto de la madera, lo cierto es que desde la segunda mitad de la década de 1730 los conflictos en relación al uso de los árboles se incrementaron exponencialmente. La causa primera de estas fricciones descansaba en el vacío legal existente en aquel tiempo sobre la tala de árboles y su distribución. No existía un reglamento general sobre el asunto y las diversas normativas de principio de siglo — 1717, 1719, 1723, 1735- eran de carácter general y se referían especialmente al reconocimiento de bosques y distancias que debían reservarse para la Marina, aunque no parece que ninguna de estas disposiciones legales se aplicara en América (Aranda, 2003, p. 13). Como consecuencia, la costumbre había determinado en Cuba la extensión de los asientos privados, mediante la cual diversos hacendados, ganaderos o comerciantes contrataban con la Marina la tala y acarreo de determinadas maderas a precios convenidos. Es a través de este canal como se relacionaron desde tiempo atrás las élites locales con la madera destinada a fines navales.

La segunda causa de conflicto está relacionada con aspectos políticos. Los juegos de poder entre Montalvo y Acosta, el gobernador y el virrey de México, y las facciones en Madrid, generaron un clima propicio para que las élites locales sacasen provecho obteniendo beneficios, muchas veces de tipo social, escorándose a conveniencia hacia uno u otro bando. En las décadas de 1730 y 1740 el principal elemento de este complicado escenario de equilibrios inestables eran las contratas para el astillero, principalmente de madera.

Por de pronto, el nuevo gobernador de La Habana de la década de 1730, Juan Francisco de Horcasitas, fue instruido por Montalvo para que se evitaran en el futuro violaciones de los espacios arbolados que estaban destinados a servir a la construcción naval, así como a suprimir las prácticas abusivas de los hacendados, en un conflicto típico en la zona entre quienes buscaban sus propios intereses respecto a la madera los comerciantes y hacendados - y las autoridades vinculadas al uso de esta materia prima con fines constructivos y sus propios clanes de élites locales ${ }^{3}$.

AGMAB, Arsenales, 7191, Acosta a Rodrigo de Torres, 10 de abril 1734. 
Mientras tanto, el negocio controlado por Acosta le generaba suculentos beneficios más allá de su vinculación con la construcción naval. El propio ministro Patiño, su gran valedor, le había permitido vender madera libremente a los buques mercantes entrantes en el puerto - es decir, a los particulares - siempre y cuando fuese a buen precio $^{4}$. La idea era obtener beneficios para la Real Hacienda que fuesen reinvertidos luego en maderas de calidad para los buques. Este proyecto es interesante por cuanto prueba que el uso de la mencionada madera aún seguía siendo libre en Cuba, al menos parcialmente, y gracias a la inexistencia de un plan general sobre la canalización de los recursos arbóreos en relación con los programas de rearme naval. Igualmente, prueba que las actividades mercantiles privadas eran tan importantes como el propio uso estatal de la madera para los nuevos navíos. Sin embargo, todo ello iba a cambiar rápidamente.

En 1738 Montalvo obligó a Acosta a firmar un contrato para la construcción de una nueva fragata, si bien con duras condiciones respecto al uso de la madera sita en los almacenes ya existentes ${ }^{5}$. La lucha por ella comenzaba a adquirir tintes dramáticos. El comisario tenía sus propias ideas, y no estaba dispuesto a permitir al constructor, que legalmente aún poseía el asiento de maderas, que siguiera aprovechando sus vínculos con ciertos hacendados para adquirir masivamente maderas que en muchos casos eran desaprovechadas o, como se ha visto, vendidas más tarde por canales privados. Montalvo, que estaba fuertemente presionado por Madrid para aumentar el ritmo constructivo, deseaba sutilmente maximizar los recursos, disponiendo de un volumen de maderamen suficiente para atender los encargos, pero no un acopio masivo que lesionaba los intereses de la Hacienda.

El golpe de efecto decisivo contra Acosta por parte del comisario de Marina vino en 1740, cuando, bajo los auspicios de éste, se firmó un asiento general con la Compañía de La Habana para la construcción de diez navíos durante una década. La Compañía se obligaba a hacer asimismo la motonería a los buques, aspecto que no entró en el antiguo asiento de Acosta, así como a compartir con éste la madera para el arsenal. En caso de que se le solicitase, debía también proveer de maderas a los arsenales peninsulares y suministrar, por el mismo tiempo de diez años, las raciones ordinarias y de dietas, géneros sueltos y otras piezas para los navíos de la armada destinados a este puerto, con un descuento del 5\% en relación con el asiento que en 1738 tenía Pedro Miguel García Menocal, rico miembro de una poderosa familia local con ramificaciones también en el negocio de la madera. Igualmente, debía ampliar el arsenal con un nuevo y fuerte cercado de paredes altas y se obligó al calafateado completo de los navíos (Serrano,

Archivo General de Simancas (en adelante AGS), AGS Marina, 305, carta del gobernador a Patiño, 24 de julio de 1735 .

AGMAB, Arsenales, 7191, copia del contrato, La Habana, 7 de agosto de 1738. 
2018, p. 98). Además se permitía a la Compañía, fiscalizada por el ministro de Marina, usar libremente los montes de la isla para el corte de maderas, tanto a sotavento como a barlovento, prohibiéndose a cualquier otra persona el uso de los mismos.

En esta nueva coyuntura, las autoridades locales desplazaron lentamente el control de la madera hacia pequeñas contratas canalizadas por Montalvo y fiscalizadas con el dinero de la Compañía. Este procedimiento generó la inserción de decenas de actores locales, de pequeños empresarios, en la industria del maderamen con fines navales y propició una notable mejora del suministro. Así, el corte de madera fue bastante bien durante todo el año 1747 y 1748, ya que las autoridades locales, empezando por Montalvo, pusieron a disposición de los implicados en estas labores todos los recursos disponibles, incluyendo varios cientos de yuntas de bueyes ${ }^{6}$.

A partir de este momento se observó un sustancial pero lento cambio de las principales familias cubanas, tradicionalmente ligadas al negocio del azúcar y tabaco, respecto al negocio de la madera. Casi todas las grandes familias siguieron suministrando recursos al astillero y generando suculentos beneficios; sin embargo, éstos derivaban más de los préstamos a la Real Hacienda que de contratos mercantiles (Kuethe, 1991, pp. 17-20). La mayoría de éstos comenzaron a realizarse con pequeños asentistas, dueños de pequeños negocios y mercaderes locales, aunque con el paso de los años llegaron a formarse verdaderos consorcios mercantiles ligados al astillero, muy especialmente al corte y arrastre de maderas.

El experimento de la Compañía de La Habana, sin embargo, no funcionó. Esta entró en quiebra financiera a finales de la década de 1740 y fue forzada a dejar su contrata en 1749 (Gárate, 1993, p. 98). A partir de la década de 1750, y con el control del astillero en manos de Montalvo, los asuntos de la madera comenzaron a generar tensiones cada vez mayores con los grandes hacendados y dueños de ingenios azucareros. Para compensar estas fricciones, las contratas sobre el corte y arrastre fueron lentamente desplazándose hacia pequeños consorcios mercantiles y pequeños empresarios, que formaban una élite paralela a la de las grandes familias habaneras (Kuethe, 1986, pp. 79-84). Las mayores familias cubanas, que dominaban más del 60\% de los cargos públicos e institucionales de la isla, vieron en la armada un canal de aumento y prestigio social vía préstamos de capital y comenzaron a alejarse del delicado y siempre arriesgado negocio de los asientos de madera, máxime cuando éstos chocaban con la imponente personalidad de Montalvo (Chaparro, 2010, pp. 192-193).

En 1753, por ejemplo, el alférez Vicente Lafite había formado una pequeña sociedad con algunos habaneros y ofreció un asiento a la corona para la construcción de diversos navíos. Entre sus condiciones estaba la de tener manos libres para llevar a

AGS Marina, 645. 
cabo el corte de maderas en toda la isla, así como facultades para trabajar la pequeña fábrica de hierro de Matanzas y sembrar lino y cáñamo con fines constructivos ${ }^{7}$. Este no sería sino uno de muchos casos similares desde entonces.

Entre 1761 y 1762 el astillero debía construir, oficialmente, once nuevos navíos, ocho de 60 cañones y tres de 80 . Las maderas que se estimaban iban a consumir eran 3.000 piezas para los de 60 cañones y 4.000 para los de 80 . En definitiva, las cuentas de la maestranza del astillero indicaban que debían estar disponibles unas 36.000 de esas piezas de diferentes tamaños ya cortadas para estos once navíos ${ }^{8}$. Las contratas establecidas por Montalvo, que habitualmente eran muy precisas y no dejaban nada al azar, fijaron con claridad el número de buques por asentista y el lugar de los cortes de madera. Justo antes de la toma de La Habana por los ingleses, la inserción de pequeños y medianos propietarios, bien individualmente o bien mediante compañías, estaba ya fuertemente arraigada y, en gran medida, orbitaban en torno a la vieja élite de las grandes familias cubanas.

Los documentos prueban que el negocio de la madera quedaba en manos de actores privados, miembros de familias de clase media con alguna que otra excepción. Así, personajes como José Hilario Pérez y José de Aguiar, Miguel Oteiza y José de Miranda, o Manuel Barranco y Alejo Méndez, se hicieron con el monopolio del corte para el ambicioso programa de reconstrucción naval liderado por Montalvo. Todos ellos, y algunos otros más, crearon pequeños consorcios que abastecían al astillero de maderas a lo largo y ancho de la isla. Sin embargo, había individuos que pertenecían a familias de rancio abolengo en Cuba, como por ejemplo, José de Aguiar, quien teniente del ejército, formaba parte de la influyente familia Aguiar, entroncada con alguno de los apellidos más ilustres de La Habana (Nieto, 1996, p. 17). Por su parte, Miranda pertenecía también a una influyente familia, presente en Cuba desde el siglo XVI, cuyos miembros habían sido o eran alcaldes, regidores y militares a lo largo y ancho de la isla (Santa Cruz, 1988, pp. 101-112). Finalmente, Pérez era un rico propietario exitoso y vinculado a los negocios de la madera desde hacía tiempo, fruto de lo cual alguno de sus descendientes acabarían laureados con la inclusión en órdenes de caballería (Lohmann, 1993, p. 60).

Todos estos elementos apuntan a que el negocio representaba mucho más que beneficios pecuniarios. Indica que las actividades ligadas al abastecimiento de maderas para el astillero conjugaban réditos económicos, pero también prebendas sociales y políticas, y aunque los apellidos más nobiliarios de la isla no estaban —usualmenterepresentados en estas actividades, hasta la década de 1760 tenían vínculos de manera indirecta, al menos con algunos apellidos.

AGI, Ultramar, 995, carta de 8 de noviembre de 1753.

AGS Marina, 331, informe de Montalvo, 13 de abril de 1761. 


\section{La batalla por la madera con los hacendados}

La tragedia de 1762 afectó profundamente no solo la evolución del astillero, sino también el rol de la madera en el universo cubano y habanero. En efecto, las presiones francesas sobre Madrid para entrar en guerra habían dado sus frutos y en agosto de 1761 se acabó firmando un pacto ofensivo-defensivo que tendría funestas consecuencias para La Habana. Como consecuencia, España entró en guerra con Inglaterra sin estar plenamente preparada y tras un asedio y defensa numantinas por parte de las fuerzas españolas, finalmente, la plaza de La Habana tuvo que rendirse mediante capitulación el 14 de agosto de 1762. Para la armada española fue un desastre, con la pérdida de doce navíos que representaban el $20 \%$ del total de la flota de guerra y, con ellos, la pérdida de buena parte del programa constructivo de una década e ingentes toneladas de madera (Parcero, 1998, p. 95).

Lo primero que se consideró tras el desastre de 1762 fue dotar al astillero de una institución eficaz, centralizada en su organigrama pero polivalente, capaz de tomar decisiones políticas respecto a la continuación de la fábrica de navíos $\mathrm{y}$, al mismo tiempo, anclada en la realidad práctica y en la trayectoria histórica de La Habana como referente ineludible para la armada. Esta institución fue la Intendencia de Marina. La Intendencia operó exactamente al mismo nivel que las intendencias navales en España, promoviendo una profunda reestructuración de las jerarquías de poder en el astillero con objetivos delimitados y trayectorias opacas. En este sentido, los principios de eficacia en la gestión de recursos, el control de los mismos, la profesionalización de sus principales actores y la adecuación de los objetivos al proyecto político demandado por Madrid, fueron en La Habana similares al de las intendencias peninsulares tanto con Montalvo al frente como tras su desaparición en 1778 (Serrano, 2018, p. 282). Al mismo tiempo, se implementó la Intendencia de Ejército y Hacienda, la primera de América, que supondría, junto con la Intendencia de Marina, un drástico cambio a la hora de operar los negocios de la madera (Pietschmann, 1996, pp. 97-110).

Las primeras medidas y consecuencias inmediatas de esta nueva estructura político-administrativa fueron la convocatoria de Juntas de contratación presididas por el gobernador, las cuales contaban con la asistencia de Montalvo y oficiales navales. El principal asunto tratado en ellas fueron los asientos de madera y la maximización de los escasos recursos existentes tras el desastre de 1762. Igualmente, bajo su patrocinio comenzaron a reservarse áreas geográficas concretas — donde se llevarían a cabo los «cortes del rey»— para el traslado al astillero y a firmar una enorme cantidad de contratas privadas con pequeños asentistas. Aunque la madera era fundamental por motivos obvios, la mayor preocupación de los diferentes funcionarios será precisamente contar con la suficiente mano de obra como para que los precios finales no se disparasen y, 
al mismo tiempo, disponer de financiación capaz de mantener activas las múltiples tareas de la maestranza. Con el tiempo esta será una inquietud creciente, en especial cuando con la cada vez mayor lejanía de los cortes de madera, y el subsiguiente aumento de precios, la fuerza laboral en términos financieros provoque desajustes que el intendente tratará por todos los medios de compensar con el control del personal asalariado9. El 29 agosto 1763, por ejemplo, se aprobó la contrata de Agustín Piña, propuesta a su vez por Lorenzo Montalvo, aunque con precios fijos para así controlar el volumen de madera y evitar la especulación ${ }^{10}$.

Por otra parte, la aprobación en 1772 de la Ordenanza sobre pertrechos supuso un cierto giro en los negocios de Marina relacionados directamente con el uso que se daba al control de los presupuestos navales. Esta disposición creaba el cargo de comandante del Arsenal, empleo separado del de intendente, aplicándose también a los arsenales de América, incluyendo el de La Habana. La ordenanza revolucionaba así los mecanismos de control fiscal y económico, puesto que por primera vez en la historia del siglo XVIII, el intendente quedaba al margen del control del gobierno de los arsenales, manteniendo únicamente sus funciones económicas (Pérez, 2002, p. 349). La disposición de 1772 afectó decisivamente la administración interna de la Marina y provocó roces permanentes entre el comandante y el intendente. Pese a que el control interno de las finanzas seguía en manos de este último, la «gran política» económica interna de los arsenales se modificaba sustancialmente toda vez que se creaba una Junta de Departamento - una Junta Naval, integrada por el comandante, el intendente y cinco oficiales más - , que era la responsable de las decisiones de contratación, gasto de personal y vituallas. Esto dejaba al intendente en franca minoría y con un papel meramente espectador de las grandes decisiones económicas que se tomasen en ella (Merino, 1981, p. 20).

Las enormes necesidades de aumentar la construcción de navíos, los problemas financieros, siempre crónicos, y las disputas en el seno de la Junta Naval, provocaron un voraz ciclo de contratas sobre las maderas del que las grandes familias ya se habían retirado. Estas comenzaban a estar mucho más preocupadas por el incremento de sus negocios mercantiles al socaire de la regulación parcialmente liberal de 1765 que incentivaba la exportación de productos de la isla, para los que la madera era indispensable. Así las cosas, la tesorería del astillero no tuvo más remedio que acudir a la pequeña élite mercantil, muy receptiva a la enorme demanda de maderamen y atraída por la plata mexicana.

De todos los asentistas que firmaron asientos en aquel tiempo, el intendente Montalvo señalaba como los más peligrosos a los de madera, quienes sin dinero inmediato,

AGS Marina, 349, informe de 29 de agosto de 1772.

10 AGI, Santo Domingo, 2118, Junta de 29 de agosto de 1763. 
sencillamente no cumplían sus tratos. El conde de Macuriges, Lorenzo Montalvo, trató lo mejor que pudo de evitar que se implementara esta forma de fiscalización extrema, porque entendía, probablemente con acierto, que no se podía llevar el mismo tipo de control contable que por la misma época se instaurará en los astilleros peninsulares. Allá era posible equilibrar mensualmente los presupuestos con débitos y equilibrios porque la cercanía de la Secretaría de Hacienda y los recursos generales del Estado permitían a los asentistas la tranquilidad de que sus contratas se acabarían cobrando. En cambio, en La Habana, el flujo numerario que sustentaba al astillero procedía de dos únicas fuentes principales: los préstamos de la clase comercial local, con intereses directos en el astillero, y los recursos metálicos sobrantes de caja del Virreinato novohispano. Ambas fuentes de financiación eran inestables por naturaleza, a lo que se añadía el problema de que el personal del astillero y los asentistas debían cobrar en metálico y en tiempo debido. No había, por tanto, posibilidad de crear balances ficticios sobre la base de un futuro cobro asegurado.

Con tanta construcción, estas dificultades presupuestarias y en tan poco tiempo, no resulta extraño que uno de los principales inconvenientes para el relance de la fábrica naval propuesta por el intendente fuera la madera. Esta era una auténtica obsesión para Montalvo. A principios de 1769 empezó a tener algunas dificultades con el suministro, pero peor aún fueron los reproches que ciertos sectores de la ciudad le hacían por su política de cortes en los alrededores de La Habana. Hubo comerciantes, especialmente los relacionados con el sector azucarero, que le criticaron por su tendencia a esquilmar los montes en beneficio exclusivamente de la construcción naval, sin atender a las peticiones de madera del resto de la población. Este no era un tema fácil de lidiar para el intendente; no al menos desde que el rey le informó que no debía usarse demasiada madera para hacer cajones comerciales para el azúcar, pues constaba que se destrozaban grandes árboles para usar solo pequeñas partes de ellos. Montalvo tenía, por consiguiente, que hacer valer sus órdenes de rearme naval, que para él eran prioritarias, pero al mismo tiempo debía contentar a una población que, no hay que olvidarlo, en épocas de necesidad era la única capaz de aportar dinero a la Tesorería de Marina (Serrano, 2018, p. 303).

Aquí comenzaron los peores enfrentamientos con la élite local de gran poder en la isla. El marqués del Real Agrado trató de hacer acopio de madera sin consultar a nadie, incluso usando la de los bosques cercanos al puerto, que se necesitaban para la fábrica de bajeles. Montalvo tuvo que denunciarlo, y tras un largo proceso, la justicia dio la razón al intendente y el marqués se vio obligado a pagar los daños causados ${ }^{11}$. Aunque este enfrentamiento no se daría habitualmente en época de Montalvo, sí evi-

AGI Cuba, 1097, informe de 23 de octubre de 1768. 
denciaba que había una relación causa-efecto entre los problemas con la madera y el aumento de la construcción naval.

En paralelo, un informe emitido por Gautier a principios de 1772 dejaba clara la necesidad de buscar una solución al asunto. Muchos de los mejores bosques españoles habían sido ya esquilmados. Al respecto, sus ojos, y los de muchos ingenieros navales, se volvieron hacia América, y en concreto hacia Cuba. Gautier defendía la calidad ancestral de sus bosques, pero se hacía eco de las noticias que desde La Habana le indicaban que el costo de la tala de árboles se estaba incrementando cada día más. El informe no lo especifica, aunque existen indicios que apuntan a que otros lugares de América trataron de aprovechar esta coyuntura para arrebatar a La Habana su monopolio en la fábrica naval o, al menos, el abastecimiento de maderas. Se pensó incluso en las costas de Trinidad o de Honduras como lugares alternativos donde buscarla, ya que Gautier tenía claro que «solamente con la madera de América se pueden continuar las operaciones de los arsenales de Europa $»^{12}$.

En consecuencia, los esfuerzos por conservar madera para la construcción se multiplicaron, en especial después de los alarmantes informes de Gautier. El asunto preocupaba a Montalvo, pues cuestionaba la posición del astillero, toda vez que éste no solo debía continuar sus habituales responsabilidades, sino que además tenía que multiplicar sus envíos a España y cuidarse de que su costo no fuera excesivo. Montalvo recordó que ya se había prohibido a los lugareños cortar madera de cedro para hacer cajas de azúcar, y que lo que realmente le molestaba era la intromisión de personas que nada sabían del asunto. Aprovechó esta controversia para acusar a Juan Antonio Colina y a Juan Bautista Bonet — jefe de escuadra también, llegado recientemente a la ciudad - de haber enviado informes a Madrid dando cuenta del deplorable estado del corte de maderas y de su almacenaje, sin tener la menor visión ni conocimiento de lo que hablaban (Valdéz-Bubnov, 2011, pp. 377-379). Esto no hizo sino agudizar los problemas, que se trasladaron rápidamente al escenario político interno del astillero, al tiempo que continuaba la dinámica de contratas privadas con la élite empresarial isleña y las disputas con los grandes hacendados sobre el uso de la madera con fines mercantiles. En efecto, Bonet, al hacerse cargo de la construcción de bajeles (Serrano, 2018, p. 314), se hizo responsable del corte de maderas, de la asignación de contratas y de todos los aspectos logísticos tocantes a este aspecto. Montalvo solo mantenía, que no era poco, la fiscalización económica de la actividad. Es decir, Bonet decidía en qué se gastaba y cómo se construía, pero Montalvo decidía cuánto y de qué manera. Sin embargo, si los planes del intendente chocaban frontalmente con los del comandante, este tenía todas las bazas jurídicas en su mano para acabar imponiéndose. Esto, lejos 
de ser una solución, auguraba enfrentamientos jurisdiccionales graves entre ambas autoridades, ya que la línea que separaba ambos compromisos era realmente delgada y afectaba decisivamente al correcto despliegue del maderamen con fines constructivos.

Mientras tanto, Bonet trataba de conocer la situación real del corte de maderas y sus posibilidades futuras; aprendiendo de este modo, por así decir, el oficio. Como era habitual cuando alguien llegaba a un puesto de alta responsabilidad, ordenó una investigación minuciosa para tratar de fijar prioridades y evaluar las posibles responsabilidades de sus antecesores. Tras elegir a varios funcionarios que recorrieron toda la jurisdicción de La Habana en busca de información sobre la situación de los bosques, pudo elaborar un interesante documento en el que no parecía que la materia prima para la construcción estuviese en peligro. El informe mencionaba no menos de 17 lugares diferentes donde encontrar maderas, así como más de un centenar de aserraderos particulares ${ }^{13}$. El problema, en este caso, era que algunos de esos lugares estaban bajo la «protección» o uso mercantil de algunas grandes familias con ingenios de azúcar, por lo que el choque de intereses estaba servido.

A fin de evitar un enfrentamiento directo con los hacendados, se buscaron otras opciones. Se ordenaron cortes alternativos en Cumaná, pero se vio que la madera no tenía ni la calidad de la cubana ni los costos compensaban ${ }^{14}$. Esto no evitó, empero, el choque con las élites locales. Los asientos para el astillero y el cada vez más agudo problema de las maderas absorbió un tiempo que no había, porque en Cuba los intereses de la clase comerciante respecto a los negocios empezaron a friccionar con los del astillero. Cada vez se hizo más patente que la burguesía mercantil estaba más interesada en quemar madera en los ingenios azucareros o en fabricar cajas para transportar productos, que en ceder a los intereses de una Marina que pagaba mal y tarde. De hecho, Moreno Fraginals incidió en su día en que este hecho fue patente a causa de la importancia que tenía el uso de la madera cubana (Moreno Fraginals, pp. 10-15).

La muerte de Montalvo en 1778 y el estallido de la guerra contra los ingleses al año siguiente (1779-1783) agudizaron los problemas referentes a la madera, con el añadido de que desde la década de 1770 los ingenieros peninsulares demandaban enormes cantidades para sus propios arsenales. Este momento es clave, porque a las tensiones ya latentes se unió la necesidad de ingentes compras para acometer las operaciones militares al tiempo que se debía continuar la fábrica naval. Los gastos fueron, naturalmente, astronómicos. De esta manera, alrededor del 20\% de las compras estaban relacionadas con la madera o palos diversos, mientras que los tejidos, metales, lastre, ladrillos, jarcia y provisiones para las carenas suponían no menos del

AGS Marina, 350, Bonet a Arriaga, 30 de noviembre de 1772.

AGS Marina, 352, Bonet a Arriaga, 27 de enero de 1775. 
$25 \%$ de las erogaciones del astillero. Por su parte, los gastos derivados del suministro al hospital representaban alrededor del 8\%, mientras que, finalmente, los de personal, en años sin guerra, no superaban el 25\% del total (Serrano, 2018, p. 398). Esto fijaba la política de suministros al astillero en el nivel de prioridad máxima, muy por encima de los suministros que necesitaba el ejército que en muchos casos provenían directamente de España.

Concomitante con lo anterior, estuvo el Decreto de Libre Comercio de 1778 que extendía, de facto, los beneficios a la práctica totalidad de los puertos importantes americanos y cuyos efectos fueron visibles desde la década de 1780 (García-Baquero, 1997). Como resultado del inmediato beneficio mercantil obtenido por las exenciones fiscales o las rebajas impositivas, los ingenios de azúcar se multiplicaron exponencialmente en poco tiempo anunciando una futura guerra por la madera. Esta constituía un bien indispensable no solo para las cajas donde se transportaba, sino también para la quema y producción del azúcar. Si hacia 1759 La Habana contaba con 88 ingenios activos y alrededor de una decena en construcción que representaban el 75\% del total de azúcares elaborados en toda la isla, a finales 1780 existían ya 180, elevándose a 228 en 1792 (García, 2006, p. 44). Naturalmente, esto tuvo un impacto directo sobre la exportación de azúcar que pasó a duplicarse entre 1780 y 1791, con más de 244.592 arrobas (Funes, 2000, p. 85).

Hasta la época de Montalvo, la cesión de derechos sobre la explotación de la madera a los hacendados y pobladores estaba determinada tanto por el gobernador como por el comandante de Marina. Ambos tenían jurisdicciones independientes y por tanto intereses diversos. Mientras que el gobernador solía atender los requerimientos de los poderosos, sabedor de que dichos favores le eran devueltos de múltiples maneras, como por ejemplo, con préstamos a la Real Hacienda, el comandante de Marina era extremadamente celoso del cumplimiento de su objetivo estratégico, que no era otro que reservarse la mejor madera para los buques y el envío de cantidades crecientes a España. Así las cosas, con Juan Bautista Bonet al frente de la comandancia desde 1772 el maderamen se transformó en un asunto político y jurisdiccional.

Por Real Orden de 20 de noviembre de 1776 se creaba la Junta de Maderas cuyos integrantes en La Habana eran todos los altos responsables políticos, significativamente, el gobernador, el comandante de Marina, el comisario de Marina y el intendente de Ejército y Hacienda ${ }^{15}$. Estas Juntas en La Habana fueron todo menos un recinto de paz y tranquilidad. Allá se produjo hasta finales de siglo una obcecada batalla por el control de la tala de árboles y su utilización. Con Bonet al frente de los asuntos navales, no solo quedó relegado Montalvo a un papel subsidiario, sino que se mostró con

AGI Santo Domingo, 1238, Junta de maderas, 3 de septiembre de 1783. 
cruda realidad cómo los intereses militares de la armada pugnaban ferozmente contra el creciente poder de la clase comerciante local. Bonet, un militar advenedizo que ni entendía ni le interesaba realmente la élite cubana, se centró en cumplir su labor, que no era otra que mantener un flujo creciente de excelente madera cubana hacia Ferrol y Cádiz, mientras acopiaba parte de ella para el programa de rearme naval.

En esta nueva y dramática coyuntura, la administración directa de los cortes ganó claramente la batalla a los asentistas con consecuencias no del todo gratas para la Marina. Los aspectos relacionados con la madera de uso naval complejizaron las relaciones hasta provocar tensiones que a su vez obligaron a solicitar a Madrid mediación. Si antes de 1772 la gestión de los cortes de madera había quedado delimitada por una, como mínimo, cordial relación entre el gobernador de turno y el intendente, el desplazamiento de Montalvo dejaba al gobernador frente al irresoluble problema de contentar al comandante de Marina y los intereses locales. Hasta el inicio de la guerra en 1779 estos conflictos quedaron relativamente ocultos y contenidos ante la presencia en escena de Montalvo que, aunque limitado en poder, aún conseervaba esa imponente figura e influencia que mantuvo a Bonet con cierto ánimo conciliador. Pero la muerte del intendente en 1778, las necesidades de la guerra y la reactivación del programa naval después de 1785 (Serrano, 2018, p. 430), avivaron la contienda, al punto de provocar verdaderos choques frontales ante intereses divergentes.

Las disposiciones legales que antes de 1772 trataban de establecer normas que facilitasen el acceso a las maderas por parte de todos habían quedado obsoletas desde esa fecha, tanto por el incremento de las necesidades de la Marina como por la incorregible propensión de los lugareños a incumplir los lugares asignados ${ }^{16}$. Con las disputas in crescendo, solo cabía tratar de establecer algún tipo de acuerdo entre los hacendados y las autoridades.

El primer intento de arreglo tuvo lugar en la Junta de Maderas del 2 de octubre de 1779. Allí, se expuso sobre la mesa el conflicto en toda su magnitud y se produjo el primer choque frontal entre el gobernador y capitán general, Luis Unzaga y Bonet, y el comandante de Marina. A los intentos del primero por conciliar los intereses de los vecinos y de los poderosos azucareros con las necesidades de la armada, se oponía el dictamen de Bonet, deseoso de construir navíos y enviar a España cantidades crecientes de madera. Para el gobernador era importante en cambio mantener el control -igualmente simbólico como máxima autoridad en Cuba - de las licencias sobre los cortes de la misma, máxime si se tiene en cuenta que el principal prestamista de la Hacienda local eran precisamente el grupo de hacendados y dueños de ingenios azucareros, entre otros comerciantes. Por su parte, Bonet se obcecaba en hacer cumplir

AGI Cuba, 1159, Bando de 27 de agosto de 1772. 
tanto las Ordenanzas de 1748 como las más recientes, de 1772 y 1776, defendiendo con uñas y dientes su jurisdicción sobre el astillero. De esta forma, lo que aconteció en aquella junta, donde no se llegó a ningún acuerdo y se solicitó dictamen al Consejo de Indias, fue una pugna entre dos poderes paralelos, el ejército y la armada. Además de ello, este asunto afectaba a jurisdicciones políticas diferentes en España. Mientras Bonet escribía con desesperación a su superior Valdés ${ }^{17}$ que, como ministro de Marina estaba naturalmente muy interesado en que se cumplieran los designios navales, el gobernador de Cuba acudía de la misma manera al ministro de Indias, José de Gálvez, de quien dependía. Aunque la relación entre ambos secretarios era cordial y comprensiva, se tuvo que recurrir al Consejo de Indias para dilucidar un problema que era ya, claramente, político. Para los hacendados, la pretensión de la armada de reservarse en propiedad los montes y bosques para su uso exclusivo atentaba contra los derechos de propiedad reglados en las Leyes de Indias ${ }^{18}$.

Finalmente, urgía resolver la cuestión lo más rápidamente posible, porque oficiales de la comandancia de Marina habían llegado a expropiar al madera que los particulares y hacendados presuntamente habían recogido y acopiado de manera ilegal en lugares reservados para la armada, amenazando así con convertir el problema en un asunto de orden público. El dictamen del Consejo de Indias de 4 de agosto de 1784 trató de conciliar ambas posturas, estableciendo una delgada línea roja jurisdiccional respecto a la disputa, aunque lo cierto es que dejó el problema sin solución hasta finales de siglo ${ }^{19}$ : suspendió las disposiciones previas que había otorgado el gobernador, al conceder determinadas licencias de cortes de madera, y decidió que el comandante de Marina, habida cuenta la necesidad urgente de maderas que había en España y para la fábrica en La Habana, se reservaría para sí la elección de los mejores sitios y bosques fines navales, estableciendo en ellos los cortes del rey con funcionarios propios, es decir, se ampliaba la administración directa de la gestión maderera a los lugares que el mencionado comandante determinase. Por su parte, el gobernador quedaba «con igual facultad y autoridad» respecto al resto de lugares y tipos de madera, los cuales eran, obviamente, de menor calidad. Haciendo valer la Marina este fallo, dispuso reservarse 40 leguas a sotavento y barlovento de La Habana, 6 leguas de fondo a la costa del norte y 20 por la banda del sur desde el surgidero del Batabano sin fondo ${ }^{20}$.

Naturalmente, esto supuso una auténtica declaración de guerra para los hacendados que durante años lucharon por ampliar sus lugares y privilegios de extracción ante

\footnotetext{
$17 \quad$ Ambos se conocían desde las trágicas jornadas de 1762. Además Valdés, antes de asumir el Ministerio, en 1783, gozaba del pleno apoyo y respaldo del poderoso Floridablanca (Serrano, 2018, p. 404).

18 Ibidem.

19 AGI Santo Domingo, 1242.

$20 \quad$ AGI Santo Domingo, 1252. Resolución de 4 de octubre de 1784.
} 
el cada vez mayor negocio, y beneficio, del comercio libre internacional. La armada, por su parte, logró el control exclusivo de las maderas cubanas de mejor calidad pero a un costo muy elevado.

En efecto, al desplazar la Marina al sector privado del acopio y ofrecimiento al astillero de las maderas más apropiadas, la comandancia hubo de hacerse cargo de todo el proceso. Desde el estudio e inspección de los lugares idóneos, hasta el propio corte, traslado y transporte, todo recayó en la administración de la armada. Por de pronto, en las décadas de 1780 y 1790 tuvieron que construirse decenas de buques de diferente porte para estos menesteres ${ }^{21}$. Por ejemplo, Borja, el comandante de Marina, informaba en agosto de 1784 que había decidido fabricar dos embarcaciones para la conducción de maderas a un costo de 19.738 pesos, cantidad realmente importante toda vez que no se trataban de navíos de guerra propiamente dichos. De manera significativa, todo esto disuadió a los asentistas de «colaborar» con la Marina, en especial sabiendo las duras condiciones contractuales imperantes que impuso, como ya explicó Romero Landa. Las dos últimas contratas que hemos detectado datan de 1775, en manos de José Melchor de Acosta, para cortes de madera, y de Andrés Yung para arboladuras ${ }^{22}$; así como la contrata de Juan Blanco de 1781, en su caso para el corte y traslado de maderamen ${ }^{23}$.

Por otra parte, la comandancia de Marina se vio forzada a buscar componentes navales que no existían en Cuba o bien eran de mala calidad, como las arboladuras. Y estas solo se podían obtener en las costas del virreinato novohispano. Con la presión de trasladar a España —en pleno despegue del programa naval de Valdés - muchas maderas de calidad y de todos los tipos necesarios, las autoridades navales de La Habana tuvieron que negociar — esta vez sí- con asentistas novohispanos, bien directamente, bien a través del virrey, y obviamente, en condiciones probablemente nada ventajosas para la armada, la cual se tenía que comprometer además a enviar buques para su transporte a La Habana, y de ahí a España, con el subsiguiente costo añadido a sus ya exhaustas arcas (Andrade, 2006, pp. 93-97).

El control directo y prácticamente absoluto, mediante administración directa de todo el proceso de adquisición, utilización y transporte de la madera, fue una de las causas del colapso financiero del astillero de La Habana. Los enormes costos para las arcas de la Tesorería de Marina se hicieron inaceptables a finales de la década de 1780 y los últimos años del siglo. El presupuesto solicitado para 1784, por ejemplo, mostraba a todas luces la presión existente sobre las arcas de la armada en Cuba en relación con este asunto. En efecto, la proyección de las necesidades financieras para

\footnotetext{
21 En concreto, 10 navíos, 8 fragatas y 15 unidades menores, principalmente bergantines y paquebotes de guerra, (Serrano, 2018, pp. 530-531; Valdés, 1813, pp. 321-322).

22 AGS Marina, 353, Acuerdos de la Junta naval, 27 de marzo de 1775.

23 AGMAB Arsenales, 5514, Expedientes de asientos.
} 
ese año fijaba los sueldos anuales para las tripulaciones de las catorce embarcaciones de conducción de maderas en 19.440 pesos; las piezas de arboladuras traídas por particulares desde Nueva Orleans demandaban 22.500 pesos; mientras que, finalmente, los cortes del rey, que incluían a un gran número de funcionarios, boyadas y esclavos, otros 118.200 pesos. En total, 160.140 pesos, o si se quiere, el equivalente a un navío de 64-70 cañones ${ }^{24}$. Los costos de la tala y transporte de la madera fueron extraordinariamente altos y no siempre relacionados con su uso en La Habana, ya que, en la última década del siglo, casi toda ella era exportada o reexportada a España. La guerra abierta con los hacendados, las necesidades acuciantes de la armada y la obligación de administrar directamente los asuntos de la madera acabaron suponiendo un importe inmenso. Año tras año, la madera representaba normalmente para la Marina el tercer elemento de gasto, tras los sueldos y los víveres.

El inflexible control de la Marina de los recursos forestales cubanos no se detuvo ahí. En 1789 se publicó en La Habana un bando que eliminaba las restricciones que tenía la armada fuera de los cortes asignados por el propio comandante, reservándose desde ese año todo lo que se juzgase por más conveniente al rey en el seno de la Junta Naval. La extensión del monopolio de la Marina sobre los bosques y su aprovechamiento con fines constructivos, y principalmente su remisión a España, se hizo desde entonces sobre toda la isla (Funes, 2000, p. 145).

Los hacendados reaccionaron después de que la aguda crisis financiera del astillero se plasmara en una Real Orden de 9 de agosto de 1794, por la que se ordenaba una reducción general de los gastos navales en La Habana - la cancelación de facto del programa constructivo-, incluyendo el cultivo de maderas, su arreglo y separación, destinándose a las labores de acopio y traslado a 100 presidiarios del astillero, en vez de a los peones para ahorrar dinero ${ }^{25}$.

Efectivamente, tras la erección del Consulado de La Habana, el 4 de abril de 1794, los hacendados solicitaron y obtuvieron en 1800 la limitación de los bosques bajo control de la Marina y una mayor representatividad en la nueva Junta de maderas conformada desde esa fecha. Asimismo, se les aceptó liberar los cortes de madera para construcción de buques en las haciendas situadas a 30 leguas a barlovento y sotavento (Jordán, 2006, p. 87).

Los elementos de confrontación entre la Marina, las autoridades locales y los hacendados deben interpretarse a la luz de los intereses mercantiles de estos últimos, muy alejados de los deseos políticos de las dos primeras. Paradójicamente, si el Reglamento de 1778 liberalizó el comercio y favoreció a largo plazo los intereses de la

AGMAB Consignaciones, 3776, Junta naval, 22 de septiembre de 1783.

AGMAB Consignaciones, 7210. 
corona, en La Habana esto supuso un desligamiento paulatino, pero inevitable, entre la burguesía mercantil y la política naval. Las enormes cantidades de cajas de azúcar exportadas, lejos de ser un elemento anecdótico, habría que interpretarlas como un factor analítico en la batalla por la madera; una batalla que tenía fuertes connotaciones mercantiles, y por tanto fiscales, para el ámbito de la hacienda regional. El acopio de madera representó un punto de no retorno en las relaciones mantenidas entre la élite mercantil, cuyos ingresos aumentaron ostensiblemente después de 1783, y la comandancia de Marina. Si los hacendados perdieron la batalla política por el control de los montes cubanos, también se tomaron su revancha frente a la armada, al retirarles el apoyo financiero - préstamos - que antaño le ofrecían. Como resultado, la Tesorería de Marina tuvo que depender, sobre todo, de los ingresos exógenos — situado naval-y de las aportaciones que, graciosamente, en determinados casos le otorgaba la Tesorería General, es decir, sus rivales del ejército.

Pero lo verdaderamente significativo fue la dejadez con la que decenas de ricos hacendados y miembros del consulado miraban ahora a las urgencias de la armada. Así pues, se daba la paradoja de que mientras los efectos del libre comercio beneficiaban a la Tesorería General, aumentando las posibilidades de ofrecer colaboración financiera a la Marina, la clase mercantil se sustrajo de ese apoyo ante la concomitancia de dos factores. Por una parte, los beneficios netos de las actividades comerciales, mucho más jugosos que el riesgo de prestar a la armada y esperar tal vez varios años a recibir los fondos a cambio de un premio realmente poco atrayente — entre un $2 \%$ y un $4 \%$ mientras que por otra, con este desinterés frente a los problemas de la comandancia se tomaban la revancha en su lucha por el control de la madera.

De igual modo, la poderosa clase comerciante habanera ligada a los negocios del azúcar gozó del apoyo del gobernador en su eterna disputa con la Marina por el control de las maderas. En esta coyuntura resultaba bastante natural que, en caso de necesidad, los préstamos de los hacendados fuesen a la Intendencia de Ejército y no hacia la Tesorería de Marina, virtualmente abandonada por la élite de negocios durante los últimos años del siglo XVIII.

\section{Conclusiones}

En el astillero de La Habana y, en general, en Cuba, a lo largo del siglo XVIII solo hubo dos batallas realmente importantes. Una se refería a la perenne lucha por obtener dinero, bien de los impuestos locales, bien de los préstamos o bien, y fundamentalmente, de México. La segunda, más importante, se refiere al control de los bosques y sus maderas. Una batalla esta que se prolongó durante todo el siglo y que, en nuestra opinión, no favoreció a los intereses de la armada. Los hacendados y las 
familias ricas cubanas siempre mostraron un inusitado, aunque no gratuito, interés por colaborar con las autoridades políticas y militares de Cuba, puesto que eran muy conscientes del prestigio y de las posibilidades de ascenso social que le otorgaba su aparente generosidad. Durante años canalizaron esta ayuda respecto a la madera de manera directa, pero, sobre todo, como intermediarios de pequeños y medianos propietarios, ansiosos por ascender también socialmente y/o entroncar con los grandes apellidos de la isla. Sin embargo, las sucesivas medidas liberalizadoras que se sucedieron entre 1765 y 1778 representaron un cambio de rumbo. La paradoja estriba en que, mientras la corona ampliaba sus gastos militares como consecuencia del aumento de las rentas, se le escapaba de las manos el negocio de la madera. Los ricos hacendados se percataron de que esas mismas medidas le eran extraordinariamente beneficiosas como elementos a través de las que canalizar sus iniciativas mercantiles.

Como consecuencia de todo ello, la armada entró en guerra abierta con las grandes familias; una guerra que, en efecto, ganó, pero a un costo enorme. La armada debió hacerse cargo directamente de todo el proceso relacionado con las maderas, proceso para lo que no estaba preparada y que la empujaba a manos de ansiosos especuladores pequeñoburgueses que vieron en esta etapa — el último tercio del siglo- su oportunidad. El resultado fue que los costos del corte, traslado y uso de la madera para el astillero se dispararon astronómicamente, obligando incluso a la administración a adquirir costosas maderas fuera de la isla. Así, lo ganado por un lado, se perdía por otro. Mientras que existía un aumento de las posibilidades de gasto gracias a las reformas fiscales, los costos igualmente se disparaban, muy especialmente respecto de la madera.

Los hacendados, por su parte, cerraron filas y el consulado les abrió la puerta a competir con la propia administración con alternativas mejores y más baratas. Incluso sabemos que obtenían madera del exterior a precios más bajos traídas de los mismos mercados que ellos surtían con sus productos.

Así las cosas, la batalla política por la madera fue una larga lucha de desgaste que acabó perdiendo la administración pública y, por supuesto, la armada. En esto, el sector privado ligado a esas grandes familias demostró que la libre competencia y la desregulación mercantil eran refractarias a la misma existencia del Estado fiscalmilitar español. 


\section{Bibliografía}

Amores Carredano, Juan Bosco (2015), «La Habana en la crisis del imperio español en América: una visión comparada», Anuario de Estudios Atlánticos, $\mathrm{n}^{\circ}$ 62, pp. 1-18.

Andrade MuÑoz, Germán Luis (2006), Un mar de intereses. La producción de pertrechos navales en Nueva España, siglo XVIII, México, Instituto Mora.

Aranda y AnTón, Gaspar (2003), «Los montes de la jurisdicción de la Marina», Revista de Historia Naval, Año XXI, nº 81, suplemento $\mathrm{n}^{\circ} 5$.

Chaparro, Álvaro (2010), «Educación y reproducción social de las élites habaneras (1776-1804)», Revista Complutense de Historia de América, vol. 36, pp. 185-207. https://doi: 10.5209/rev_RCHA.2010.v36.9.

Funes Monzote, Reinaldo (2000), De bosque a sabana: azúcar, deforestación y medio ambiente en Cuba, 1492-1926, México, Siglo XXI.

GÁRATe OJAnguren, Monserrat (1993), Comercio ultramarino e ilustración. La Real Compañia de La Habana, San Sebastián, Real Sociedad Vascongada de Amigos del País.

Gárate Ojanguren, Monserrat (1999), «Títulos nobiliarios en la Cuba española (XVIII-XIX)», Hidalguía: la revista de genealogía, nobleza y armas, $\mathrm{n}^{\mathrm{o}} 276$, pp. 617-636.

García-Vaquero, Antonio (1997), «Los resultados del libre comercio y 'El punto de vista': una revisión desde la estadística», Manuscrits: Revista d'història moderna, $\mathrm{n}^{\circ} 15$, pp. 303-322.

GARCía Fuentes, Lutgardo (1991), «Economía indiana en el siglo XVII», en Navarro García, Luis (coord.), Historia de las Américas, Sevilla, Universidad de SevillaAlhambra, vol. 2, pp. 183-231.

GARcía Rodríguez, Mercedes (2006), «Ingenios habaneros del siglo XVIII: mundo agrario interior», América Latina en la Historia Económica, n 26, pp. 41-75. http://dx.doi.org/10.18232/alhe.v13i2.380

JoRdÁn ReYes, Miguel (2006), La deforestación de la isla de Cuba durante la dominación española (1492-1898), Madrid, Universidad Politécnica, [Tesis doctoral inédita].

Kuethe, Allan J. (1986), Cuba: 1735-1815, crown, military and society, Knoxville, University of Tenesse Press.

Kuethe, Allan J. (1991), «Havana in the Eighteenth Century», en Knight, Franklin W. y Liss, Peggy K. (eds.), Atlantic Port Cities: Economic, Culture and Society in the Atlantic World, 1650-1850, Tennessee, Univ. of Tennessee Press, pp. 13-39. 
Lohmann, Guillermo (1993), Los Americanos en las órdenes nobiliarias, Madrid, CSIC, vol. I.

NiEto, Rafael (1996), Genealogías habaneras, Madrid, Hidalguía, vol. 4.

Merino, José P. (1981), La Armada española en el siglo XVIII, Madrid, Ministerio de Defensa.

Moreno Fraginals, Manuel (2001), El ingenio. Complejo económico social cubano del azúcar, Madrid, Crítica.

PARCERO, Celia (1998), La pérdida de La Habana y las reformas borbónicas en Cuba, 1760-1773, Ávila, Junta de Castilla y León.

PÉrez Fernández-TuréGano, Carlos (2002), «La fiscalización económica en la Marina española del siglo XVIII», en Teijeiro de la Rosa, Juan Miguel (coord.), La Hacienda Militar, Madrid, Ministerio de Defensa, pp. 303-422.

Perona, Dionisio A. (1998), Los orígenes del Ministerio de Marina. La Secretaría de Estado y del Despacho de Marina, 1714-1808, Madrid, Ministerio de Defensa.

Pichardo, Hortensia (1973), Documentos para la historia de Cuba, La Habana, Editorial Ciencias Sociales, vol. I.

Pietschmann, Horst (1996), Las reformas borbónicas y el sistema de intendencias en Nueva España. Un estudio político administrativo, México, FCE.

Quintero, José (2004), «La madera en los pertrechos navales», Tiempos Modernos, $\mathrm{n}^{\mathrm{o}}$ 10. http://www.tiemposmodernos.org/tm3/index.php/tm/article/view/42/63

Santa Cruz, Francisco Xavier (1988), Historia de familias cubanas, La Habana, Editorial Hércules, vol. II.

SERrano Álvarez, José Manuel (2006), «Juan de Acosta y la construcción naval en La Habana, 1717-1740», Revista de Historia Naval, nº 93, pp. 7-32.

SERrano Álvarez, José Manuel (2018), El astillero de La Habana en el siglo XVIII. Historia y construcción naval, 1700-1805, Madrid, Ministerio de Defensa.

VAldés, Antonio José (1813), Historia de la isla de Cuba, y en especial de La Habana, vol. 1, Oficina de la Cena, La Habana.

Valdéz-Bubnov, Iván (2011), Poder naval y modernización de Estado: politica de construcción naval española (siglos XVI-XVIII), Madrid, Iberoamericana. https:// doi.org/10.31819/9783954878994 